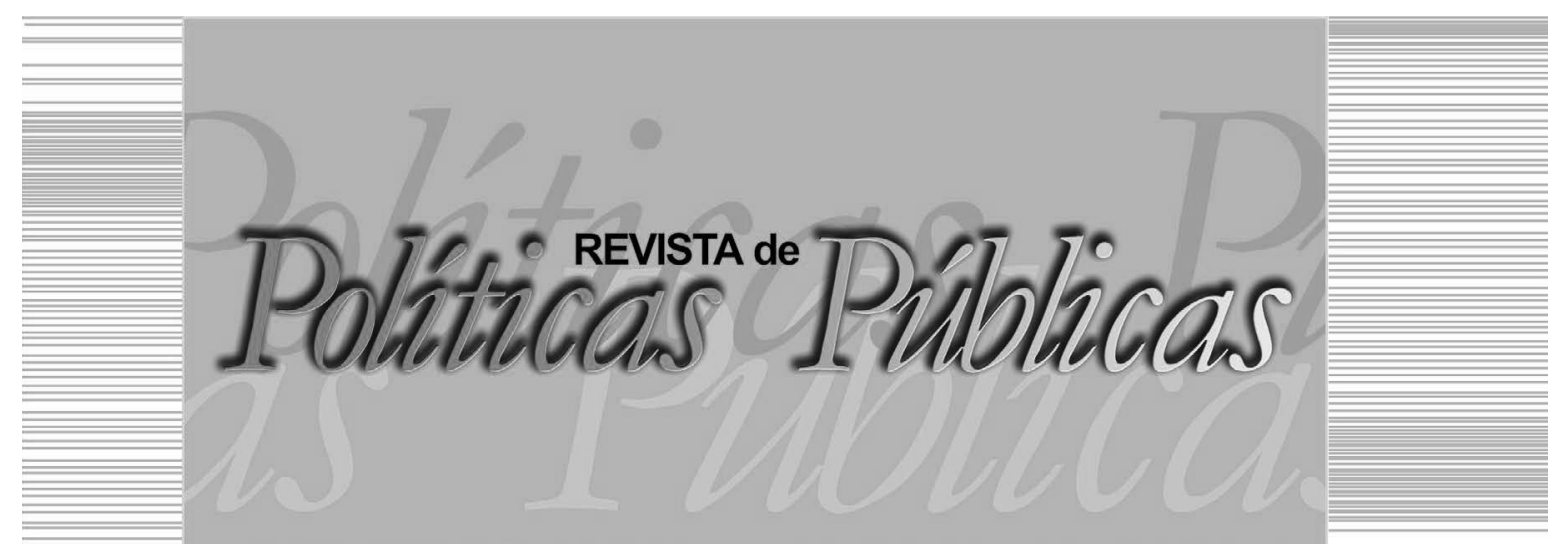

\title{
O FUTURO DO TRABALHO NO BRASIL: modernização e miséria
}

\author{
Fabrícia Pavesi Helmer ${ }^{1}$ \\ Rodrigo da Rocha Rodrigues ${ }^{2}$ \\ Raquel de Matos Lopes Gentilli ${ }^{3}$
}

\section{Resumo}

Este trabalho tem como objetivo discutir o impacto das orientações neoliberais nas relações de trabalho, considerando as reformas ocorridas na Consolidação das Leis do Trabalho e na atual reforma trabalhista em curso. Metodologicamente, trata de um texto teórico realizado a partir de pesquisa bibliográfica em artigos indexados, na legislação trabalhista, no projeto de lei aprovado e em reflexões técnicas relacionadas ao tema trabalho. Verifica que o impacto da reforma trabalhista na desregulamentação do trabalho no Brasil só tende a se consolidar com sua legalização, além de se considerar que o projeto societário neoliberal se consagra no Brasil em mais uma modernização conservadora. Como conclusão, acredita que as perspectivas futuras, mediante a reforma em curso, só intensificarão a precarização do trabalho, a pobreza, a informalidade e a desigualdade social no Brasil.

1 Assistente Social, Mestranda em Políticas Públicas e Desenvolvimento Local na Escola Superior de Ciências da Santa Casa de Misericórdia de Vitória (EMESCAM). E-mail: fabriciahelmer2@hotmail.com

2 Graduado em Ciências Jurídicas e Sociais, Mestrando em Políticas Públicas e Desenvolvimento Local pela Escola Superior de Ciências da Santa Casa de Misericórdia de Vitória (EMESCAM). E-mail: 3rr@bol.com.br

3 Assistente Social, Doutora em Serviço Social pela Pontifícia Universidade Católica de São Paulo (PUC-SP), Professora do Curso de Serviço Social e do Mestrado em Políticas Públicas e Desenvolvimento Local da Escola Superior de Ciências da Santa Casa de Misericórdia de Vitória (EMESCAM). E-mail: raquel.gentilli@emescam.br / Escola Superior de Ciências da Santa Casa de Misericórdia de Vitória - EMESCAM: Av. Nossa Senhora da Penha, 2190, Santa Luiza - Vitória, ES. CEP: 29045-402 
Palavras-chave: Reforma trabalhista, modernização conservadora, precarização do trabalho, neoliberalismo.

THE FUTURE OF WORK IN BRAZIL: modernization and misery

\begin{abstract}
This article has the objective of to discuss the impact of neoliberal orientations on labor relations, considering the reforms that have taken place in the Consolidation of Labor Laws (CLT) and the ongoing labor reform in progress. Methodologically, this is a theoretical text based on bibliographical research in indexed articles, labor legislation, the approved law and technical reflections related to the work. Verifies that the impact of the labor reform on the deregulation of labor in Brazil only tends to consolidate with its legalization and it is considered that the neoliberal corporate project consecrates more conservative capitalist modernization. As a conclusion, it is believed that the future prospects, through the ongoing reform, will only intensify the precariousness of labor, poverty, informality and social inequality in Brazil.

Key words: Labor reform, conservative modernization, precariousness of work, neoliberalism.
\end{abstract}

\title{
1 INTRODUÇÃO
}

A Consolidação das Leis do Trabalho (CLT) como norma legislativa de referência e regulamentação das leis relativas ao Direito do Trabalho e ao Direito Processual do Trabalho no Brasil representou, historicamente, a proteção social do trabalhador, por parte do Estado, fruto de uma ampla e longa luta dos movimentos sociais pelos direitos trabalhistas.

Apesar disso, de modo gradual, a CLT foi sofrendo emendas, desconstruções e retrocessos, causados, em sua maioria, pela modernização conservadora, desde a ditadura militar, e mais recentemente, pelos ditames da ordem neoliberal, que realiza uma ofensiva de maximização dos lucros através da estratégia de precarização das relações de trabalho, associada a práticas políticas, sociais e ideológicas de dominação. Preconiza um Estado mínimo, fazendo retroceder os direitos trabalhistas, sociais e políticos, duramente conquistados.

A lógica neoliberal aportada no Brasil a partir da década de 1990 vem pressionando os governos a flexibilizarem as relações de contrato de trabalho e a própria legislação trabalhista, ou seja, pressionam no sentido de o trabalho se tornar precarizado e que se des- 
montem os direitos do trabalho que foram conquistados com muita luta e embates ao longo da nossa história recente, legitimando a regressão de direitos.

Com a crise jurídico-parlamentar de 2016 e a instalação de Michel Temer no poder, presenciou-se uma intensa movimentação política no Congresso Nacional no sentido de encaminhar a votação de uma proposta tida como modernizante, porém ao introduzir tais alterações, configurou-se não como uma reforma, mas como uma contrarreforma à legislação trabalhista celetista.

A reforma trabalhista em curso representa um grande retrocesso aos direitos dos trabalhadores e se encontra estruturada sob os pilares da terceirização, da flexibilização do trabalho e da precarização das formas de contrato de trabalho, que em conjunto, legalizam a precarização das condições de trabalho.

Obedecendo à lógica hegemônica do capitalismo globalizado, a reforma trabalhista significou a capitulação do Congresso Nacional e do governo Temer às exigências do capitalismo global, sem se preocupar com as desastrosas consequências para a proteção do trabalho, para a geração de uma massa salarial capaz de estimular o crescimento da economia, e para a proteção social dos segmentos mais fragilizados da população.

Nessa lógica, o presente artigo objetiva discutir os impactos das orientações neoliberais nas relações de trabalho, os elementos constitutivos da reforma trabalhista em curso, bem como as repercussões nas condições econômicas e sociais dos trabalhadores. A reforma trabalhista - apresentada como modernização das relações do trabalho e da CLT -, na verdade traz sérias e desastrosas consequências às condições sociais e econômicas de segmentos mais precarizados da população brasileira, acentuando a miséria, sobretudo pela perda da proteção dos trabalhadores que a legislação trabalhista e a Justiça do Trabalho ofereciam na mediação de conflitos entre empregados e empregadores.

\section{O avanço das ideias e das práticas neoliberais nas relações de trabalho no Brasil}

Com os avanços das ideias neoliberais no mundo e, especificamente no Brasil a partir da década de 1990, observa-se a ocorrência de dois fenômenos centrais nas condições e relações de traba- 
lho: a financeirização da economia e a precarização das relações de trabalho. Sader (2013) já observara que o neoliberalismo instituído submetia as relações de trabalho a processos de informalização que significaram sua precarização na prática, ferindo pressupostos legais e constitucionais que ainda estavam em vigor na legislação trabalhista, retirando, na prática, direitos essenciais dos trabalhadores de forma ilegal.

O desemprego, desde sempre estrutural no Brasil, agravou-se rapidamente, operado pela ampliação da exclusão de trabalhadores do mercado de trabalho, em decorrência da crescente introdução de tecnologias de automação, e pela alta rotatividade da mão de obra que se torna desqualificada e obsoleta, rapidamente, devido à velocidade de mudanças tecnológicas introduzidas no processo produtivo.

O neoliberalismo torna-se uma realidade ideológica de defesa dos interesses do capital globalizado, favorecendo a naturalização da desigualdade social e a busca pela eficiência produtiva e pela competitividade entre trabalhadores e entre empresas para conseguirem fazer frente à competitividade do mundo da globalização. Sob esse enfoque, Sposati (2000, p. 64) registra que "[...] o maior impacto da globalização se manifesta na desregulamentação da força de trabalho, no achatamento de salários e no aumento do desemprego". Essa lógica passou a ditar o ideário de um projeto societário a ser implementado nos países capitalistas para restaurar o crescimento estável, tendo como pressupostos a reestruturação produtiva, a privatização acelerada, o enxugamento do Estado e a desproteção social.

As contradições da reestruturação produtiva do capital e sua racionalidade ampliam enormemente as dimensões de socialização do capital na mesma dimensão, inversamente proporcional em que agudiza e intensifica a "irracionalidade social visível" e a "dessocialização" do já precário mundo do trabalho. A produção, no padrão do toyotismo, na sua selvagem lógica de "produção enxuta", tem expulsado enorme contingente de "trabalho vivo" do processo produtivo, tornando-o supérfluo (do ponto de vista do capital), lançando as sociedades no "uso decrescente dos bens e serviços", paradoxalmente, apontando para a lógica da "reestruturação destrutiva do capital." (ALVES, 2011, p. 23).

Tais relações de trabalho se apresentam na forma de trabalho precário, fragmentado e heterogeneizado (ANTUNES, 1997) e vêm criando uma nova sociabilidade, onde amplos segmentos da força de 
trabalho estão sofrendo dificuldades adicionais de inserção no mercado de trabalho, em decorrência dos novos padrões de capacitação, qualificação e das exigências dos novos padrões de polifuncionalidade, cada vez mais complexos e exigentes, constituindo o que $\mathrm{Al}-$ ves $(2011$, p. 23) denomina "[...] sociometabolismo da barbárie que explicita as dilacerantes contradições vivas do capital".

A mundialização do capital recente confirma a tendência, segundo a qual, em seu processo, já se evidencia um aprofundamento das relações entre crescimento econômico, pobreza e desigualdade mais significativa e profunda, tornando ainda mais distante as possibilidades de distribuição dos bens socialmente produzidos e de redução das desigualdades sociais. Contemporaneamente, além de ampliar os processos de desordem, desigualdade, injustiça e miséria, o "[...] desenvolvimento capitalista é, necessária e irredutivelmente, produção exponenciada de riqueza e produção reiterada de pobreza." (PAULO NETTO, 2007, p. 142).

A reflexão acima mostra como, de modo gradual, a CLT foi ao longo dos anos sendo abolida por meio de legislações infraconstitucionais que negaram várias cláusulas da Constituição Federal (CF) de 1988. Há que se destacar, no entanto, que a ofensiva neoliberal, iniciada em 1990, encontrou um obstáculo relativo a partir de 2003, com a eleição de Luís Inácio Lula da Silva (PT) para Presidente da República. O neodesenvolvimentismo de Lula, e, posteriormente de Dilma, paralisaram esse processo histórico de desconstrução da CLT, sem, entretanto, revertê-lo no sentido de abolir a nova ordem da precariedade salarial instalada pela lógica neoliberal. (ALVES, 2017).

O choque da nova ordem mundial capitalista no Brasil deu-se com um mundo de trabalho desqualificado e já precarizado por conta da regulação flexível instaurada na década anterior. Com a crise do modelo neodesenvolvimentista dos governos do PT, o movimento de precarização do trabalho que havia se estagnado anteriormente, retorna com vigor num momento de reação neoliberal conservadora, marcada pela crise jurídico-parlamentar de 2016 que levou ao poder Michel Temer. (ALVES, 2017).

A reação conservadora do Congresso Nacional em apoio ao governo Temer significa o desmonte dos empecilhos jurídicos que constavam ainda na CF de 1988 e na CLT e que impunham obrigações trabalhistas aos empresários, que não mais querem assumir. Tal 
prerrogativa possibilitada ao capital significa a abolição dos direitos conquistados por trabalhadores nas últimas décadas. Visam, portanto, a maximização dos lucros do capital e dos interesses do bloco neoliberal no poder e a minimização dos direitos dos trabalhadores.

A reforma trabalhista vem se processando num contexto de uma das mais profundas crises econômicas e políticas que o país já viveu, com severo aumento do desemprego e de grave crise fiscal. Reformas se justificam como necessárias, quando visam recuperar a competitividade da economia, a redução do custo do trabalho, a flexibilização da capacidade de iniciativa das empresas, a recuperação dos empregos, a modernização da legislação e do sistema de relações de trabalho e para gerar o equilíbrio fiscal. Entretanto, os aspectos desta reforma trabalhista apresentam elementos de uma contrarreforma. $\mathrm{O}$ sentido essencial de seu texto não se encontra na modernização, mas na ampliação das formas de superexploração do trabalho no Brasil em todos os níveis e em todas as atividades. (ANTUNES, 2016).

A terceirização, a subcontratação, o trabalho em domicílio, o pagamento por peça, enfim, as várias formas de trabalho precário, que levam à informalidade das relações contratuais, favorecem a intensificação da característica de superexploração do trabalho, por meio da extração da mais-valia relativa em combinação com a mais-valia absoluta. O capitalismo contemporâneo vem produzindo a ampliação do ritmo de trabalho e a ampliação da jornada de trabalho, o que tem acarretado a superexploração do trabalho. (MEIRELLES, 2016).

Sabendo que, em um país como o Brasil, por exemplo, onde a informalidade no trabalho é uma condição histórica, é importante lembrar que a desregulamentação trabalhista promove, também, a precarização do trabalho formal. O exemplo mais contundente de precarização do trabalho formal pode ser observado em relação às horas-extras não remuneradas. As empresas passaram a trabalhar no sistema de banco de horas, onde o trabalhador fica à disposição do fluxo do trabalho institucional, representando um exemplo clássico de extração de mais-valia absoluta. (MEIRELLES, 2016).

Dessa forma, em consonância com as reformas neoliberais em curso no mundo, a reforma trabalhista votada na Câmara Federal pelo Projeto de Lei $\mathrm{n}^{\circ}$ 6787-B de 2016 (BRASIL, 2017a) e que tramitou no Senado como Projeto de Lei da Câmara de no 38 de 2017 
(BRASIL, 2017f), aprofunda a desestruturação do mercado de trabalho brasileiro, sobretudo porque legaliza os pilares da terceirização, da flexibilização ilimitada e a precarização das formas de contrato de trabalho existentes, que em conjunto, favorecem a criação de empregos cada vez mais precários.

3 A legislação do trabalho: entre a proteção e a desproteção social no Brasil

A CLT instituída em 1943, sempre foi considerada um grande avanço da classe trabalhadora brasileira, expressando historicamente as grandes conquistas dessa classe em decorrência das lutas dos movimentos sociais e suas pautas pelos direitos trabalhistas nas décadas iniciais do século XX. Nesse sentido, a CLT transformou-se em parâmetro central que balizou as relações de trabalho no país, impedindo que estas resvalassem para a pura mercantilização da força de trabalho. (COSTA, 2005).

As pautas trabalhistas dos fins do século XIX e começo do século XX decorreram de embates políticos de forças comunistas, sindicalistas e anarquistas contra as ações policiais de controle e repressão da força de trabalho pelo poder do Estado, que defendiam preceitos econômicos liberais, políticos conservadores e ideologicamente desqualificadores do ser humano. Assim, a regulação estatal da força de trabalho foi disciplinando os trabalhadores por meio do aceno do reconhecimento dos direitos trabalhistas, ligados às condições de trabalho, desde final do século XIX até início dos anos de 1930.

Sobre as condições de trabalho da Primeira República, Fausto (1988) registra que, em termos práticos, as iniciativas governamentais e as atividades legislativas em relação ao trabalho eram episódicas, setorizadas, muitas vezes postergadas. A legislação regulamentada - que abre espaço para as lutas pelas condições de trabalho, como a lei de férias e a de regulamentação do trabalho infantil -, quase sempre não era cumprida por força do "[...] lobby industrial que influencia diretamente as condições de aplicação (ou melhor, de não aplicação) da legislação aprovada pelo Congresso." (FAUSTO, 1988, p. 9).

Vianna (1996) registra que este Estado emergente se contorce entre suas ambiguidades doutrinárias do liberalismo e a prática da escravidão, sem enfrentar os desafios de superar a barbárie de uma 
sociedade tradicional, fragmentária e sem uma ossatura institucional. O Estado-nação brasileiro de inspiração liberal tolerava apenas uma sociedade civil estimulante, confinada às elites políticas e intelectuais, que induziam a pequenas rupturas na ordem senhorial-escravocrata, sem, entretanto, assumir um liberalismo econômico e político como um princípio de sua organização, em todas as suas consequências.

Mantém a estrutura econômica escravocrata e agrária, que assegurava a presença do Brasil no mercado mundial e nas relações internacionais e a presença das elites rurais na cena política e no controle do território e da população, enquanto estimulava o desenvolvimento industrial.

Apoiado em Fernandes (1975), Vianna (1996) observa que a expansão da ordem burguesa no Brasil mobiliza atores sociais da vida urbana: empresários, intelectuais, operários, militares, todos ligados às camadas médias das cidades, que passam a fomentar um caldo de cultura ideal de cariz liberal, no contexto de uma sociedade estruturada ainda pela ordem patrimonial, dando origem a manifestações sociais, a greves e a movimentos sociais, ao sindicalismo operário, às denúncias sobre o sistema eleitoral a serviço das oligarquias agrárias, à formação do primeiro partido identificado com os trabalhadores, o Partido Comunista Brasileiro (PCB) e uma rebelião de tenentes, que deu origem à Coluna Prestes.

Como consequência, forma-se um bloco político que atende às demandas por modernização econômica e social das elites econômicas, mas põe em movimento uma modernização conservadora, acolhidas por parte dos setores tradicionais das elites (de Minas Gerais e Rio Grande do Sul). Tal movimento, a chamada Revolução de 1930, sob a liderança de Getúlio Vargas, recebe apoio de parte do movimento tenentista, das camadas médias e dos setores populares dos centros urbanos.

Esse movimento político-militar marca a ascensão de Vargas e o fim do domínio agrário-exportador vinculado à produção do café, dando lugar a um projeto industrializante, ancorado num Estado forte, origem de uma política nacionalista e de cariz populista e que não se desprende das relações agrárias e tradicionais.

Para Vianna (1996), a configuração do processo revolucionário de 1930 constitui-se como revolução passiva, e a questão so- 
cial - incorporação das massas urbanas ao mundo dos direitos e da modernização econômica -, se deu como estratégia política sem, entretanto, criar condições que oportunizassem uma ruptura na ordem institucional e novas alternativas e oportunidades de vida para a grande massa da população, ainda dependente dos latifúndios e dos senhores de terra.

Esse projeto industrial, nacionalista e estatal tem por mérito passar a tratar a questão do trabalho, não mais como caso de polícia, mas como questão social, o que dá origem a uma nova perspectiva política na relação entre governantes e trabalhadores. Tal condição permitiu a Vargas contar com apoio dos "[...] trabalhadores urbanos para manter seu poder num momento de fortes dissensões entre as frações agrária-exportadora-cafeeira, a agrária não-exportadora e os emergentes setores industriais, encontrando nos tenentes outra força política importante para sua sustentação." (ANTUNES, 2006, p. 84).

Para o autor, o grande mérito político de Vargas foi trazer as classes trabalhadoras para o centro da política, para a agenda do Estado, politizando a questão social. Conseguiu representar os interesses econômicos e políticos das elites, mobilizando o apoio das classes populares, sobretudo na segunda fase de seu governo.

Vargas necessitava do apoio político dos trabalhadores para sustentar uma dominação política de novo tipo, tendo na legislação social e trabalhista o ponto constituinte deste apoio para seu governo desde 1930, tendo, na CLT de 1943, sua principal estratégia para atender às reivindicações dos trabalhadores urbanos.

Apesar de a legislação trabalhista ter sido uma demanda dos trabalhadores desde o começo do século XX, Vargas lhe atribuiu um estatuto de dádiva do Estado. Cria em torno de sua figura o mito de pai dos pobres, apesar de ser profundamente autocrático e ditatorial em relação a grupos de esquerda, reprimindo violentamente suas lideranças políticas e sindicais.

A lógica do controle e repressão foi a tônica da era Vargas também com relação à legislação sindical que, por não poder realizar disputas de classe, passou a exercer funções assistencialistas, de lazer e serviços advocatícios. A criação do imposto sindical e da lei de enquadramento sindical consolidou a lógica da intermediação do 
Ministério do Trabalho sobre os sindicatos, mecanismos existentes até os dias atuais.

A combinação da lógica da dádiva, da manipulação, da repressão política, do controle da legislação sindical e da legislação trabalhista, divulgada como concessões favorecidas pelo governo, foi a herança que Vargas legou aos trabalhadores através da CLT. A questão social tornou-se uma questão política, entretanto, muito frequentemente se recorre à repressão policial contra os direitos de manifestação dos trabalhadores e dos sindicatos.

A CLT continuaria protegendo os trabalhadores pelos próximos anos até que o governo militar fizesse as primeiras e profundas modificações em seu escopo. Sua primeira mudança acontece com a Lei $n^{\circ}$ 4.923, de 23 de dezembro de 1965, que autoriza a redução salarial de até $25 \%$ (vinte e cinco por cento) para as empresas que comprovassem dificuldades financeiras, desde que respeitassem o salário mínimo. (BRASIL, 1965).

Em 1966, o governo militar introduz outra reforma na CLT. Alegando necessidade de modernização das relações de trabalho, edita a Lei $n^{\circ} 5.107 / 66$, que criou o Fundo de Garantia do Tempo de Serviço (FGTS) em substituição à estabilidade do empregado após 10 anos de trabalho, conforme era garantido anteriormente pela CLT. $\mathrm{Na}$ avaliação de Bronstein (1997) esse foi o primeiro grande passo, com importante concretude, contra o Estado protetor de direitos trabalhistas na América Latina.

A CLT, que significou para os trabalhadores uma referência de proteção social do trabalho por parte do Estado, entretanto, com uma retórica de modernização das relações do trabalho, foi sendo modificada a cada investida do capital. Tal retórica representa mais uma peça ideológica, que um fato real, pois ao invés de se criar uma extensão protetiva ao direito do trabalho, estão sendo destruídos direitos e criadas novas formas e modalidades de exploração da mão de obra, cada vez mais precarizadas. Se tal retórica fosse real, seria necessária a expansão para mais proteção e não o que foi votado. (CAVALCANTI, 2017).

Dessa forma, verifica-se que a CLT foi sendo abolida de modo gradual e por meio de legislações infraconstitucionais que negavam as cláusulas pétreas da CF, ao constituírem um regime de um novo e precário mundo do trabalho. Observa-se que esta reforma, 
fundamentalmente, promove uma abolição generalizada de direitos, conquistados nas últimas décadas, visando atender, conforme aponta Antunes (2016), aos interesses do projeto societário de um bloco de poder neoliberal, que associa transformações tecnológicas, informacionais, reestruturação produtiva e financeirização da economia.

\section{Reforma trabalhista em curso}

$\mathrm{Na}$ condução da votação da atual reforma, pode-se verificar que seus pressupostos adulteram a concepção original da CLT, assim como a diretriz constitucional acerca da proteção do trabalho humano, conforme concebido no Brasil, desde 1943. Isso resulta do fato de o governo e dos políticos cederem às pressões dos empresários para articular a desoneração dos gastos empresariais com as folhas de pagamento, fato que acaba lesando os interesses dos trabalhadores.

Essa ofensiva consolida uma tendência que já vinha se esboçando em outros mecanismos de precarização do trabalho. Ela está visível em três principais diretrizes que foram incorporadas na atual reforma: o princípio do negociado sobre o legislado, a terceirização e a flexibilização do trabalho e da jornada de trabalho, que, em conjunto, legalizam a precarização das condições de trabalho atuais.

Uma das justificativas do governo para a reforma trabalhista está no pressuposto de que tais alterações irão beneficiar o trabalhador e aumentar a oferta de empregos. Entretanto, o que se observa é que tais elementos da reforma favorecem mais ao empresariado, livrando-o de determinados encargos atualmente existentes, desmontando toda a estrutura organizada e consolidada desde 1943, e que, na prática, nem havia chegado a abarcar a maioria dos trabalhadores.

Observa-se que a atual reforma contraria a lógica do Direito do Trabalho cujo princípio é o da intervenção do Estado na manifestação da vontade das partes para balizar o contrato de trabalho, protegendo o trabalhador. É de se supor que a ausência do Estado levará a um passado marcado pela desregulação, desproteção e precarização, como aquela realidade do começo do século XX. Assim, o que estamos próximos a presenciar é a institucionalização da precariedade do mercado de trabalho, o que já vinha acontecendo na prática. (CAVALCANTI, 2017). 
Acerca do princípio do negociado sobre o legislado, a reforma atual abre, a partir do Projeto de Lei ${ }^{\circ}$ 6787/2016 (que foi sancionado como Lei de $\mathrm{n}^{\mathrm{o}} 13.467$, de 13 de julho de 2017), a condição de negociação entre empresas e trabalhadores como prevalentes sobre o que está posto na legislação (BRASIL, 2017a). Desse modo, diz-se, juridicamente, que o negociado se coloca acima do legislado. Isso posto, observa-se que em uma situação de grande desemprego, as condições de negociação tornam-se particularmente precárias para os trabalhadores. Em face da dificuldade em fazer exigências nas negociações, ficando os trabalhadores submissos às imposições dos patrões.

Alguns outros exemplos de precarização introduzidos na nova Lei podem ser apontados, como no caso da terceirização de serviços para outras empresas menores, que, na medida em que flexibiliza direitos trabalhistas, antes líquidos e certos, passam os ônus da instabilidade para os pequenos empresários.

No lastro da atual precarização, as inovações que emergem na forma de contrato de trabalho, trazidas pela atual reforma trabalhista do governo Temer, encontra-se a modalidade teletrabalho (modalidade de trabalho realizada em casa), onde o trabalhador também passa a ser o responsável pelas despesas com a aquisição ou manutenção de equipamentos e da infraestrutura necessária para seu trabalho. Essa omissão quanto à responsabilidade do empregador abre espaço para transferência de custos e riscos das atividades econômicas para o trabalhador, em razão de sua conhecida hipossuficiência para uma livre negociação sobre as condições de trabalho.

Outra modalidade de contratação contemplada pela reforma em curso, e que afeta, sobretudo, a população mais pobre - mas não só a ela -, está na forma de contratação para subemprego, com renda inferior ao salário mínimo mensal. Essa modalidade vem inserida no contrato intermitente, que estabelece o pagamento do salário mínimo por hora, sem que seja assegurado um número mínimo de horas trabalhadas no mês. Dessa forma, o trabalhador permanece à disposição da empresa durante todo o período, até que seja convocado novamente. Ressalta-se que no caso de o trabalhador aceitar a convocação, mas não comparecer ao local de trabalho, terá que pagar multa equivalente a $50 \%$ da remuneração que lhe seria devida, ao empregador. Além da possibilidade de chegar ao final do mês 
sem nada receber, poderá ainda ter uma dívida junto ao empregador, assemelhando-se à figura da servidão por dívidas.

Sobre tais modificações, o Ministério Público do Trabalho (MPT) manifestou-se contrariamente, em Notas Técnicas, sobre as novas modalidades trazidas pela Lei em questão, pois estas introduzem a exclusão de trabalhadores das regras da CLT em relação à jornada de trabalho, o desrespeito dos limites da jornada diária e a falta de registro ou de controle dos horários do trabalho. Considerou, ainda, que a redução dos custos de produção por meio da flexibilização da lei trabalhista não levará à diminuição do índice de desemprego como se propaga, mas tão somente ao encolhimento da renda e à redução da capacidade aquisitiva dos consumidores, além da troca dos contratos de trabalho de tempo integral por contratos de tempo parcial.

Em sua alegação, o MPT observa que os contratos de trabalho temporários e em tempo parcial, introduzidos e amplamente utilizados na Europa e nos Estado Unidos, após a crise de 2008, geraram muitas controvérsias e, hoje, os organismos internacionais, e mesmo os países envolvidos, chegaram à conclusão que essas modalidades de contrações são socialmente nocivas, pois trazem desigualdades econômicas e sociais e geram instabilidade econômica e política.

As modalidades introduzidas na CLT subvertem a lógica do sistema de produção, pois transferem aos empregados os riscos das atividades econômicas, em flagrante colisão com os termos do artigo $2^{\circ}$ da Consolidação das Leis do Trabalho, além de se constituir em medida jurídica de natureza inconstitucional, entre outras coisas, por não garantir o recebimento de um salário mínimo mensal para o trabalhador, ferindo de morte a norma constitucional sobre este tema, conforme art. $7^{\circ}$ da CF de 1988. (BRASIL, 2017b, 2017c, 2017d, 2017e).

As inovações introduzidas na atual reforma favorecem o aviltamento das condições de trabalho e do reconhecimento dos direitos fundamentais do trabalhador, legitimando ações irregulares e/ou ilegais sobre as condições de trabalho, sobretudo dos trabalhadores mais jovens e mais pobres, para os quais o mercado de trabalho tem sido cada vez mais hostil e precarizado. De certo modo, quanto mais flexíveis forem as formas de pagamento dos salários e as jornadas de trabalho, melhor se constitui a reserva de mercado, e mais favorável se tornam as relações de trabalho para o empresário, pois, dessa for- 
ma, ele possui maior poder de depreciação de o salário a ser pago. $\mathrm{O}$ trabalhador que se encontra na condição de dependência e, necessitando de emprego, tende a aceitar propostas cada vez mais precárias.

Assim, esse movimento do capital cria desemprego permanente, o que Marx (1980) caracterizou como exército industrial de reserva, onde homens e mulheres que, por absoluta necessidade, se dispõem a vender sua única mercadoria de sobrevivência a baixo custo: a força de trabalho. Segundo Marx (1980, p. 733),

\footnotetext{
[...] se uma população trabalhadora excedente é produto necessário da acumulação ou do desenvolvimento da riqueza no sistema capitalista, ela se torna por sua vez a alavanca da acumulação capitalista, e mesmo condição de existência do modo de produção capitalista. Ela constitui um exército industrial de reserva disponível, que pertence ao capital de maneira tão absoluta como se fosse criado e mantido por ele. Ela proporciona o material humano a serviço das necessidades variáveis de expansão do capital e sempre pronto para ser explorado, independentemente dos limites do verdadeiro incremento da população.
}

Essa relação entre o processo de acumulação capitalista, a geração do exército industrial de reserva e, consequentemente, a formação da superpopulação relativa, constitui-se no elemento fundamental para a análise do desemprego contemporâneo.

A clássica formulação de Marx (1980), que já apontara a relação entre a acumulação do capital e a produção da miséria, serve para refletir sobre as mudanças em curso no Brasil, onde o nível de acumulação, concentração e centralização do capital tem se dado numa escala sem precedentes, tendendo a se intensificar, assim como agravar o pauperismo.

A pauperização, além de fragilizar os segmentos mais pobres, dependentes da proteção social do Estado pela via da seguridade, atinge também os trabalhadores inseridos no mercado de trabalho. Assiste-se assim, a um processo de precarização das condições de vida da população trabalhadora em geral, além do aumento da pressão por produtividade do trabalho, considerando o amplo exército industrial de reserva, inclusive de trabalhadores altamente qualificados. Essa realidade produz uma maior pressão sobre os trabalhadores, precarizando ainda mais suas condições de existência.

Desse modo, o desemprego e a regressão de direitos historicamente conquistados assumem as formas de expressões vivas da 
nova configuração assumida pelo capitalismo no Brasil. Além disso, em nome da modernização das relações entre capital e trabalho, a nova configuração, que emerge da reforma trabalhista, afeta a massa de trabalhadores celetistas e, por conseguinte, a vida da população em geral, desenhando um país mais desigual e fragmentário em sua representação social e política, reafirmando o neoliberalismo no Brasil.

\section{CONCLUSÃO}

Diante do exposto no presente artigo, que teve como propósito discutir as orientações neoliberais nas relações de trabalho (enfocando esta reforma trabalhista), concluiu-se que as perspectivas futuras, advindas da reforma trabalhista em curso, mostram um avanço da precarização, da informalidade, da contratação por horas e da intensificação do trabalho informal, levando, como consequência, à ampliação da desigualdade social, pois tende à exclusão dos sujeitos da Seguridade Social, bem como de outros recursos e políticas destinadas aos trabalhadores formais, o que desencadeia um aprofundamento da pauperização, absoluta ou relativa, e precarização de suas condições gerais de vida. (PAULO NETTO; BRAZ, 2006).

$\mathrm{Na}$ atual economia mundial, pautada pela permanente incerteza, o trabalho mantém a centralidade na vida social da classe trabalhadora. O capital ampliou as formas de exploração do trabalho na mesma medida em que ampliou e inovou as formas de acumulação. Disso resulta maior fragmentação da classe trabalhadora que, diante da flexibilização e precarização dos processos e relações de trabalho, resiste à uma complexidade cada vez maior das formas de exploração e de heterogeneização de sua identidade de classe.

Com o aumento da desresponsabilização do Estado no processo de negociação entre o capital e trabalho, o que tende a prevalecer é uma situação na qual o trabalhador se vê constrangido a aceitar todas as imposições que forem apresentadas pelo setor empresarial, especialmente em momentos de crise. Tem-se, em decorrência disso, a prática da diminuição de salários e da flexibilização das condições de trabalho, com aumento da jornada de trabalho.

Assim, em decorrência da compressão da massa salarial, diminuem-se as oportunidades, pois são reduzidas as demandas por bens de consumo e, quando se aumenta a jornada, diminui-se o número de trabalhadores empregados. Ou seja, reduz-se o emprego e 
cria-se o desemprego - como no Brasil de hoje -, e ainda de forma mais grave devido à precarização preexistente, a exemplo do que se assistiu na Europa e nos Estados Unidos após a crise de 2008. (BRAGA, 2016).

Desse modo, submeter o nosso direito ao trabalho à dinâmica do mercado total para torná-lo atrativo às práticas de trabalho precárias, atenta contra toda a sociedade brasileira e torna cada vez mais distante a possibilidade de se assegurar trabalho digno e protegido aos brasileiros, colocando em risco a sobrevivência de muitos segmentos sociais, antes protegidos pelo Estado brasileiro.

Por fim, verificou-se que o impacto da desregulamentação que legaliza a exploração do trabalhador celetista, consagra a associação de mais uma modernização tecnológica associada a uma direção política conservadora no nosso país. O crescimento econômico, assim gerado, se realizará entre os segmentos de trabalhadores protegidos por sua condição estratégica na produção, deixando os demais à própria sorte na informalidade e no risco social de serem lançados drasticamente na miséria, de uma hora para outra.

$\mathrm{Na}$ informalidade e na precariedade, vários segmentos da massa de trabalhadores tornam-se excluídos da lógica que fora consagrada pelas políticas sociais protetivas e distributivas. O Estado mínimo, consolidado nos termos da nova legislação do trabalho, torna obsoleta parte da força de trabalho, incapaz de ser absorvida nos novos ciclos de desenvolvimento econômicos e tecnológico. Dessa forma, a produção da miséria se intensifica, tornando os trabalhadores, ainda mais desiguais e desprotegidos.

\section{Referências}

ALVES, G. Reforma trabalhista, modernização catastrófica e a miséria da República brasileira. Blog da Boitempo, São Paulo, mar. 2017. Disponível em: <https://blogdaboitempo.com.br/2017/03/27/reformatrabalhista-modernizacao-catastrofica-e-a-miseria-da-republicabrasileira. > Acesso em: 3 jul. 2017.

. Trabalho e Subjetividade: o espírito do toyotismo na era do capitalismo manipulatório. São Paulo: Boitempo, 2011.

ANTUNES, R. Adeus ao Trabalho?: ensaios sobre as metamorfoses e a centralidade do mundo do trabalho. São Paulo: Cortez, 1997. 
De Vargas a Lula: caminhos e descaminhos da legislação trabalhista no Brasil. Pegada, São Paulo, v. 7, n. 2, p. 83-88, nov. 2006. Disponível em: $<$ http://files.estadoedireitossociais.webnode. com/200000002-398e93a884/Antunes,\%20Ricardo.\%20De\%20 Vargas\%20a\%20Lula.pdf>. Acesso em: 10 jul. 2017.

Temer é capaz de regredir lei trabalhista a época da escravidão. Brasil de Fato, São Paulo, 19 set. 2016. Disponível em: $<$ https://www.brasildefato.com.br/2016/09/19/temer-e-capaz-deregredir-lei-trabalhista-a-epoca-da-escravidao-diz-ricardo-antunes. html>. Acesso em: 02 jul. 2017.

BRAGA, R. A burguesia brasileira jamais admitiu a CLT.: Carta Capital, São Paulo, 14 set. 2016. Disponível em: $<$ https://www. cartacapital.com.br/politica/burguesia-brasileira-jamais-admitiu-a-clt. html>. Acesso em: 7 jul. 2017.

BRASIL. Câmara dos deputados. Projeto de Lei nº 6.787-B de 2016. Altera a Consolidação das Leis do Trabalho (CLT), aprovada pelo Decreto-Lei ${ }^{\circ} 5.452$, de $1^{\circ}$ de maio de 1943, a fim de adequar a legislação às novas relações de trabalho. Brasília, DF, 26 abr. 2017a.

Ministério Público do Trabalho. Procuradoria-Geral do Trabalho. Nota Técnica $n^{\circ} 1$, de 23 de janeiro de 2017. Altera a Consolidação das Leis do Trabalho para instituir o contrato de trabalho intermitente. Brasília, DF, 2017b.

. Nota Técnica $n^{\circ} 2$, de 23 de janeiro de 2017.

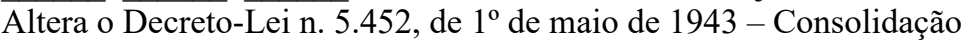
das Leis do Trabalho, e a Lei n. 6.019, de 3 de janeiro de 1974, para dispor sobre eleições de representantes dos trabalhadores no local de trabalho e sobre trabalho temporário, e dá outras providências. Brasília, DF, 2017c.

. Nota Técnica ${ }^{\circ} 3$, de 23 de janeiro de 2017. Dispõe sobre os contratos de terceirização e as relações de trabalho deles decorrentes. Brasília, DF, 2017d.

. Nota Técnica $n^{\circ} 4$, de 23 de janeiro de 2017. Dispõe sobre o contrato de prestação de serviços e relações de trabalho deles decorrentes. Brasília, DF, 2017e.

Presidência da República. Lei no 4.923 de 23 de dezembro de 1965. Institui o Cadastro Permanente das Admissões e Dispensas de Empregados, Estabelece Medidas Contra o Desemprego e de Assistência aos Desempregados, e dá outras Providências. Diário Oficial da União, Brasília, DF, 29 dez.1965. Retificado em 26 jan. 
1966. Disponível em: <http://www2.camara.leg.br/legin/fed/lei/19601969/lei-4923-23-dezembro-1965-368275-publicacaooriginal-1-pl. html>. Acesso em: 8 jul. 2017.

. Senado Federal. Projeto de Lei da Câmara nº 38, de 2017. Altera a Consolidação das Leis do Trabalho (CLT), aprovada pelo Decreto-Lei $\mathrm{n}^{\circ} 5.452$, de $1^{\circ}$ de maio de 1943 , e as Leis $\mathrm{n}^{\circ} \mathrm{s} 6.019$, de 3 de janeiro de 1974, 8.036, de 11 de maio de 1990, e 8.212, de 24 de julho de 1991, a fim de adequar a legislação às novas relações de trabalho. Brasília, DF, 14 jul. 2017f. Projeto de Lei no 6.787/2016, na Câmara dos Deputados

BRONSTEIN, A. S. Reforma laboral en America Latina: entre garantismo e flexibilidad. In: Revista Internacional del Trabajo, Ginebra, v. 116, n. 1, p. 9, p. 5-27, 1997

CAVALCANTI, T. M. Conheça os direitos que você vai perder com a Reforma Trabalhista. Blog do Sakamoto, São Paulo, 14 abr. 2017. Disponível em: <https://blogdosakamoto.blogosfera.uol.com. br/2017/04/15/conheca-direitos-que-voce-vai-perder-com-a-reformatrabalhista.html>. Acesso em: 10 jul. 2017.

COSTA, M. da S. O sistema de relações de trabalho no Brasil: alguns traços históricos e sua precarização atual. Revista Brasileira de Ciências Sociais, São Paulo, v. 20, n. 59, p. 111-170, out. 2005.

FAUSTO, B. Estado, Classe Trabalhadora e Burguesia Industrial (1920-1945). Novos Estudos, São Paulo, n. 20, p. 6-37, mar. 1988.

FERNANDES, F. A Revolução Burguesa no Brasil. Rio de Janeiro: Zahar, 1975.

MARX, K. O capital. Rio de Janeiro: Civilização Brasileira, 1980. Livro I, v. II.

MEIRELLES, G. Á. L. de. Reestruturação produtiva do capital, pauperização e desigualdade social na América Latina. Serviço Social em Revista, Londrina, v. 18, n. 2, p. 52-72, 2016.

PAULO NETTO, J. Desigualdade, pobreza e Serviço Social. Em Pauta, Rio de Janeiro, n. 19, p. 135-170, 2007.

; BRAZ, M. Economia política: uma introdução crítica. São Paulo: Cortez, 2006.

SADER, E. A construção da hegemonia pós-neoliberal. In:

(Org.). 10 anos de governos pós-neoliberais no Brasil: Lula e Dilma. São Paulo: Boitempo, 2013. p. 135-143. 
SPOSATI, A. Globalização da economia e processos de exclusão social. In: CONSELHO FEDERAL DE SERVIÇO SOCIAL; Associação Brasileira de Ensino e Pesquisa em Serviço Social; UNIVERSIDADE DE BRASÍLIA. (Orgs.). Crise Contemporânea, Questão Social e Serviço Social. Brasília, DF, 2000. Capacitação em Serviço Social e Política Social. Módulo 1, p. 61-76.

VIANNA, L. W. Caminhos e descaminhos da revolução passiva à brasileira. Caminhos e Descaminhos da Revolução Passiva à Brasileira. Dados, Rio de Janeiro, v. 39, n. 3, 1996. Disponível em: $<$ http:// www.scielo.br/scielo.php?script=sci_arttext\&pid=S00115 2581996000300004\&lng=en\&nrm=iso>. Acesso em: 15 Jul. 2017. 
